Chapter 10

\title{
Thermal Shock and Cycling Behavior of Thermal Barrier Coatings (TBCs) Used in Gas Turbines
}

\author{
Abdullah Cahit Karaoglanli, Kazuhiro Ogawa, \\ Ahmet Türk and Ismail Ozdemir \\ Additional information is available at the end of the chapter \\ http://dx.doi.org/10.5772/54412
}

\section{Introduction}

Gas turbine engines work as a power generating facility and are used in aviation industry to provide thrust by converting combustion products into kinetic energy [1-3]. Basic concerns regarding the improvements in modern gas turbine engines are higher efficiency and performance. Increase in power and efficiency of gas turbine engines can be achieved through increase in turbine inlet temperatures [1,4]. For this purpose, the materials used should have perfect mechanical strength and corrosion resistance and thus be able to work under aggressive environments and high temperatures [2]. The temperatures that turbine blades are exposed to can be close to the melting point of the superalloys. For this reason, internal cooling by cooling channels and insulation by thermal barrier coatings (TBCs) is used in order to lower the temperature of turbine blades and prevent the failure of superalloy substrates [1-4]. By utilizing TBCs in gas turbines, higher turbine inlet temperatures are allowed and as a result an increase in turbine efficiency is obtained [5]. TBCs are employed in a variety of areas such as power plants, advanced turbo engine combustion chambers, turbine blades, vanes and are often used under high thermal loads [6-11]. Various thermal shock tests are conducted by aerospace and land gas turbine manufacturers in order to develop TBCs and investigate the quality control characteristics. Despite that fact, a standardized method is still lacking. The reason lies behind the difficulty of finding a testing method that can simulate all the service and loading conditions. Present testing systems developed by the engine manufacturers for simulation of real thermal conditions in engines consist of; burner rig thermal shock testing units, jet engine thermal shock testing units and furnace cycle tests [16-20]. In this study, thermal cycle and thermal shock behavior of TBC systems under service conditions are examined, and a collection of testing methods used in evaluation of performance and endur- 
ance properties and recent studies regarding aforementioned concerns are presented as a review Study consists of the following chapters; 1 . Introduction, 2. Thermal Barrier Coatings (TBCs), 2.1 An Overview of TBCs, 2.2 Structure and function of TBC systems, 2.2.1 Substrate material, 2.2.2 Bond Coat, 2.2.3 Top Coat, 3. Thermal Shock and Cycling Behavior of Thermal Barrier Coatings, 3.1 Thermal Shock Concept, 3.2 Thermal Cycle/Shock Tests for TBCs, 4. Summary, 5. Acknowledgment, 6. References.

Including the introductory chapter, the study consists of four parts;

1.Chapter: The aim of the study is explained. An introduction is given as; general characteristics and application of thermal barrier coatings in gas turbine engines, and thermal cycle/ shock characteristics under service conditions.

2.Chapter: Thermal Barrier Coating (TBC) systems are presented and also production, structure and characteristics are explained.

3.Chapter: Thermal shock and cycle behavior of TBC system applications in gas turbines is given. Testing methods and criteria is presented. Evaluation of TBC systems after thermal shock/cycle tests is given and microstructural evaluation is mentioned.

4.Chapter: The findings of given studies are summarized and results are presented.

\section{Thermal barrier coating (TBC)}

\subsection{An overview of TBCs}

A typical TBC system, which is used in gas turbine engines to thermally protect metallic components from aggressive environmental effects, consists of a superalloy substrate material, a metallic bond coat for oxidation resistance, a ceramic top coat (such as $\mathrm{ZrO}_{2}$ stabilised with \% 6-8 $\mathrm{Y}_{2} \mathrm{O}_{3}$ ) for thermal insulation and a thermally grown oxide layer (TGO) that forms at the bond coat-top coat interface as a result of bond coat oxidation in service conditions $[2,15,21]$.

\subsection{Structure and function of TBC systems}

The main function of TBCs is to provide thermal insulation against hot gasses in engines and turbines and thus reduce the surface temperature of the underlying alloy components [21-22]. To do this, while the coated parts are cooled inside, the heat transfer through TBC to the component should be kept low. With approximately $300 \mu \mathrm{m}$ thick YSZ top coat, it is possible to achieve a temperature drop up to $170{ }^{\circ} \mathrm{C}$ between the top coat surface and substrate [22-24]. Figure 1 shows a TBC system applied on the turbine vane and its temperature gradient.

Heat insulation property of TBCs can be utilised in gas turbines in two different ways. In turbines where a TBC system is applied, either the service life of the component is increased by keeping the working temperature of the engine unchanged and thus decreasing temperature of the underlying substrate, or the efficiency is increased by increasing the working temperature of the engine to a level at which the temperature of the coated substrate is same 
as the uncoated substrate temperature.[23]. TBC systems that are produced in two different ways with conventional methods are shown in Figure 2 [25].

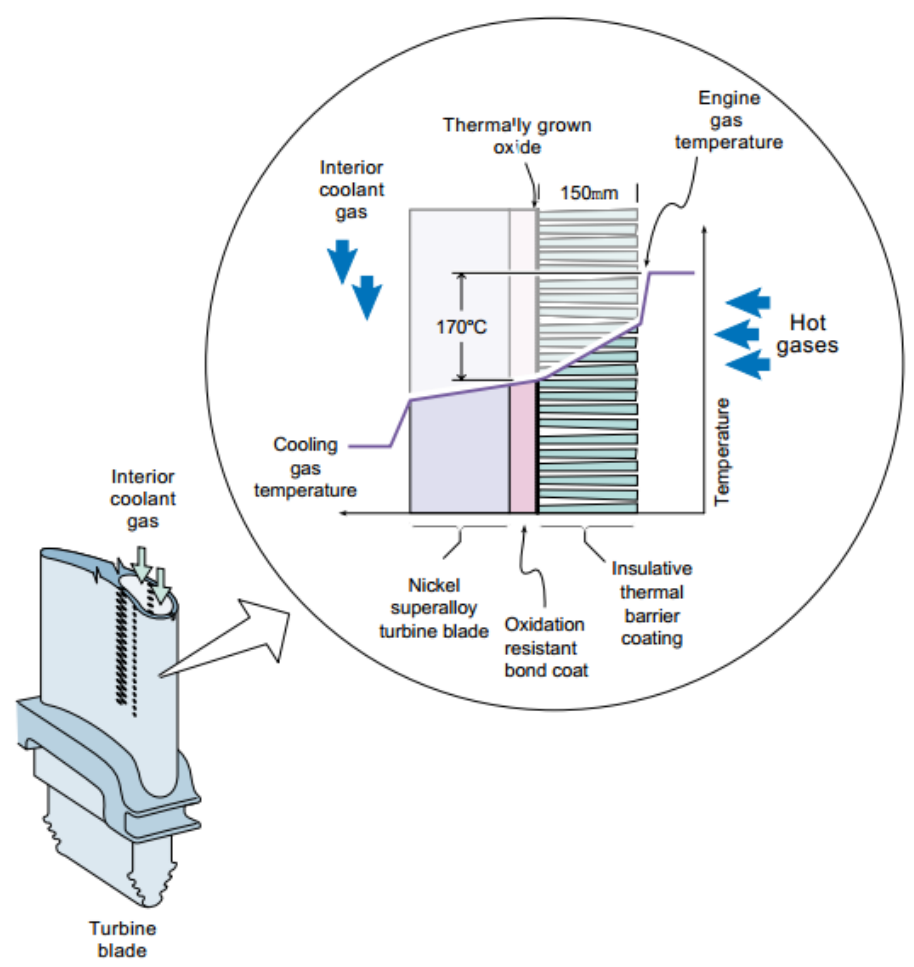

Figure 1. Representation of a TBC structure which is applied to turbine vane to serve as a thermal insulator and the heat gradient in the system [24].

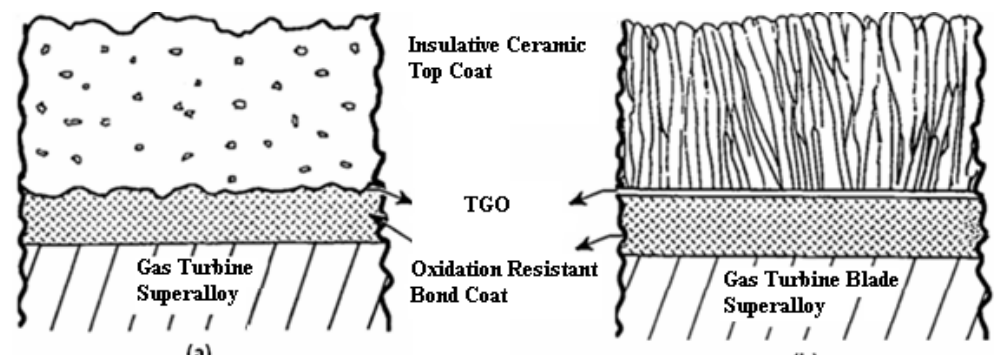

(a)

(b)

Figure 2. TBC structures produced with different methods: a) produced by APS method, b) produced by EB-PVD method [25]. 
Top layer is employed to achieve the desired temperature reduction. The lower the heat that crosses the ceramic top layer is, the more effective the cooling and hence the lower the component's surface temperature will be. To achieve this goal, the top layer should be chosen from a material with a low thermal conductivity. Another way to decrease the thermal conductivity is to increase the thickness of top layer. However it should be considered that by an increase in thickness, the weight of the component and the residual stresses in the coating will also increase. In addition, since the heat conduction distance is higher in a thicker top layer, heat transfer rate will decrease which may result in a surface temperature that exceeds the ceramic materials limits [22].

The temperature decrease with the use of TBCs provides many advantages. First of all, with the decrease in the rate of the heat transferred to the component, service temperature and indirectly productivity can be increased. Or by decreasing the temperature on the component, the substrate material that forms the component is enabled to show properties close to the room temperature properties. Besides, creep can be reduced with the component's temperature decrease as well. In addition, by means of TBCs, the protection against chemical damages, such as oxidation, is achieved by reducing the oxidation rate through the reduction in temperature and appropriate bond coat material selection [26-28]. How TBCs perform the mentioned tasks can be better understood by examination of the materials and structures of the layers that form TBC. General structure of TBCs is explained below by examining every layer (i.e. substrate, bond and top coat layers and TGO that forms by bond coat oxidation) in detail and according to their functions.

\subsubsection{Substrate material}

Substrate is in fact the basic material already available in coating system and the coating is placed on it. So, substrate is the main element to be intended to protect. Ni based superalloys are generally used in gas turbines as substrate material. The main reason for this selection is that superalloys can protect their strength under high temperatures such as $2000^{\circ} \mathrm{F}\left(\sim 1100^{\circ} \mathrm{C}\right)$. In order to increase the creep resistance at high temperatures, substrate is produced with directional grains or single crystal structure [22, 29-30]. A general composition of a conventionally used Inconel 718 super alloy is given in Table 1 [31].

\begin{tabular}{lllllllll}
\hline \multicolumn{7}{l}{ \% Chemical Composition } \\
\hline $\mathrm{Cr}$ & $\mathbf{N i}$ & $\mathrm{Nb}$ & $\mathrm{Mo}$ & $\mathrm{Ti}$ & $\mathrm{Al}$ & $\mathrm{Cu}$ & $\mathrm{C}$ & $\mathrm{Fe}$ \\
\hline 19.0 & 52.5 & 5.1 & 3.0 & 0.9 & 0.5 & 0.15 max. & 0.08 max. & Balance \\
\hline
\end{tabular}

Table 1. Chemical composition of Inconel 718 superalloy [31].

While the working temperatures of superalloys are quite high, coatings are used in today's gas turbines to increase working temperature in the turbine even higher and to extend the service life of the parts/components. As can be seen in Figure 3, working temperatures of gas turbines are already so close to the melting temperature of elements comprising superalloy components [32]. 


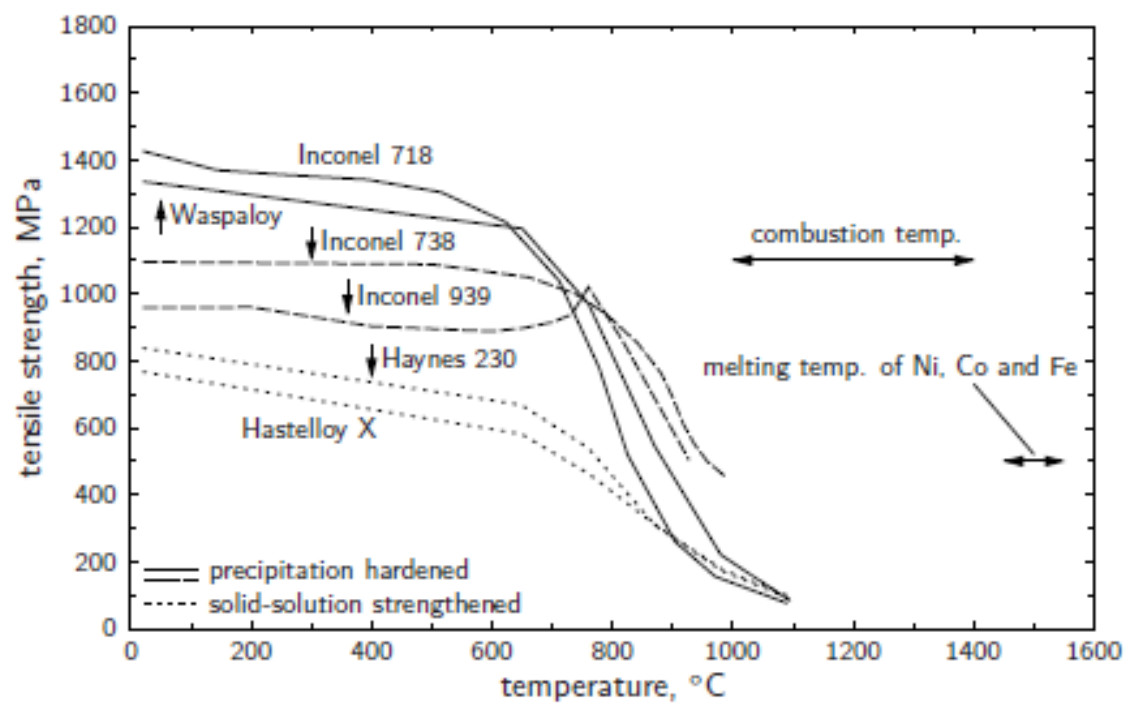

Figure 3. Tensile strength of some superalloys as a function of temperature [32].

Because of the various environmental conditions that turbine blades are exposed to, turbine inlet temperatures have greatly increased since 1940s. Today's commercial and military aircrafts have turbine inlet temperature respectively over $1500^{\circ} \mathrm{C}$ and $1600^{\circ} \mathrm{C}$ and are expected to reach $1760{ }^{\circ} \mathrm{C}$ or more at the end of 2015 , and this obviously shows the need for thermal barrier coatings. Turbine blades work under much harder conditions than any other component in the engine due to high temperature and stresses they are exposed to and the rapid temperature changes they undergo during (thermal) cycles. Moreover, they are also faced with oxidation and corrosion due to hot gasses and chemicals in the working environment. Because of all of these reasons, turbine blade components should have properties such as high corrosion resistance, creep resistance, and fatigue strength in the service. In order to meet these properties, a large proportion of the materials used in making of today's modern airplane gas turbine engines consist of superalloy materials [31].

\subsubsection{Bond coat}

Bond coat has two main functions in TBC systems. First of these functions is to increase the adherence between ceramic top coat and substrate. Second function, which cannot be performed by top coat due to its porous structure, is to protect the underlying material from chemical attacks such as oxidation [26,33]. In order for the bond coat to continue its first function, a material with suitable thermal expansion ratio should be selected [24]. This way, stresses which occur between top coat and substrate because of the thermal expansion and shrinkage during heating and cooling, can be kept at a minimum. Considering that bond coats are conventionally produced from metal alloys with high thermal expansion coefficients and 
that top coats are produced from ceramics with low thermal expansion coefficient, the tension between these surfaces should be expected to decrease by a decrease in expansion coefficient of the bond coat material [34].

Porous structure of the top coat and high diffusivity of oxygen ion in this layer enables the surface oxygen to reach lower layers [35]. Thus, it is the duty of the bond coat to protect the substrate against chemical attacks like oxidation. In order to fulfil this duty, bond coat contacts with oxygen and creates an oxide layer on top coat and interface surface. This layer, which is thinner than $10 \mu \mathrm{m}$ and forms on the bond coat surface during service, is called TGO [23].

Considering the mechanisms mentioned in this part, TGO layer is desired to consist of a homogeneously distributed, continuous and dense $\alpha-\mathrm{Al}_{2} \mathrm{O}_{3}$ [36]. However, there will be various spinel and metallic oxides apart from alumina in such a structure. In fact, oxides other than $\alpha-\mathrm{Al}_{2} \mathrm{O}_{3}$ are seen to form in time at TGO layer [37]. The reason why TGO is desired to consist of $\alpha-\mathrm{Al}_{2} \mathrm{O}_{3}$ is that oxygen permeability of this alumina phase is low [36,38]. Because if an oxide layer has low oxygen permeability, growth rate will also be low and failure stemming from TGO will be postponed. Material selection in bond coat should be designed suitably in order to achieve the above-mentioned properties.

\subsubsection{Top coat}

Top coat is the outermost layer, which contacts with the hot working gasses in gas turbine and so isexposed to theengine'sworking temperature. Thebasicfunction of topcoatistoprovidethermal isolation to the underlying layers [31,39]. A top coat should have some basic properties to achieve this objective. These properties are; high melting temperature (to keep coating structure when in contact with hot gasses), low thermal conductivity (to fulfil its thermal insulation function), thermal expansion coefficient in accordance with the underlying superalloy (to prevent the mismatch between layers during thermal cycles), resistance to oxidation and corrosion (because service environment include oxygen and some other gasses at high temperature), strain tolerance (in order to resist thermal shocks during thermal cycles) [22,40-41].

Most of the properties above are general characteristic properties of ceramics. A ceramic material that includes third and fifth properties as well will be a suitable material for top coat. Conventionally, top coat consists of a tetragonal structured zirconia. Pure zirconia undergoes phase transformation at $1170^{\circ} \mathrm{C}$ and forms a monoclinic phase by diffusionless transformation. This situation causes a volum expansion of about \%4 [42]. Volume change is undesirable because it may cause tensile stresses in the material. Therefore, to avoid transformation from tetragonal phase to monoclinic phase, yttria is added to zirconia. By doing so, metastable tetragonal phase of zirconia is formed and tetragonal phase is stabilised in low temperatures. This metastable tetragonal phase will not transform to monoclinic phase in low temperatures. But if sufficient time and temperature is provided, it transforms to stable tetragonal phase and cubic phase. Stable tetragonal phase that forms under this condition can than transform to monoclinic phase under low temperatures [43-44]. The basic property that makes YSZ a suitable material for top coat is that, along with its high thermal stability, it has low thermal conductivity and high thermal expansion coefficient. Unlike ceramics like $\mathrm{Al}_{2} \mathrm{O}_{3}$ that are unstable at high temperatures due to their polymorph properties, YSZ material has a highly 
stable structure. [45-46]. As shown in the Figure 4, while YSZ's thermal conductivity is low with respect to ceramics such as $\mathrm{Al}_{2} \mathrm{O}_{3}$ and $\mathrm{MgO}$, its thermal expansion ratio is higher than ceramics such as $\mathrm{SiO}_{2}$ or mullite that has low thermal conductivity[24,45].

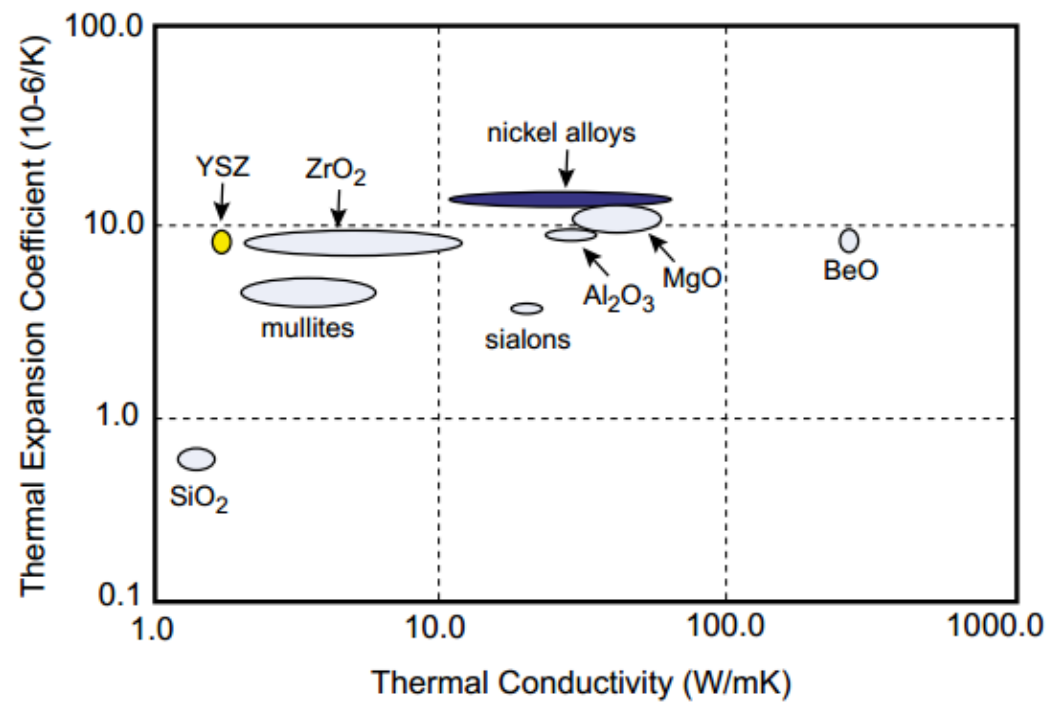

Figure 4. Representation of thermal expansion coefficient and thermal conductivity properties of various materials [24].

According to Figure 4, while thermal expansion ratio of $\mathrm{Ni}$ based substrate alloys is $14-16^{*} 10^{-6} \mathrm{~K}^{-1}$, thermal expansion ratio of YSZ is about $9^{*} 10^{-6} \mathrm{~K}^{-1}$. Considering that working temperatures in gas turbines can be as high as $1400^{\circ} \mathrm{C}$ and it undergoes thermal cycle during service period, it can easily be understood how thermal expansion mismatch can cause failure and how important it is for the top coat expansion coefficient to be close to bond coat $[27,32]$. With these properties, top coat can provide only the first of the two basic functions of TBC systems, which is heat insulation. Besides, the protection of top coat against corrosion and oxidation remain as an issue due to high oxygen permeability of this layer. The main reason of high oxygen permeability in zirconia top coat is high gas permeability due to microcracks and porosities. However, ionic diffusion can also contribute to oxygen permeability [35,47]. When the high working temperatures of the engine are taken into account, the chemical damages that are caused by the penetrating gases may reach significant levels. Differences in strain tolerances may occur according to deposition method. While tolerance in plasma spray coatings is related to porosities between splats and voids like cracks, tolerance in coatings produced by EB-PVD is related to columnar growth and unattached columns $[12,48]$. When all these are taken into account, YSZ materials can be seen to be suitable for production of the top coat of TBCs for gas turbine components and superalloy parts with both APS and EB-PVD methods [49]. 


\section{Thermal cycle/shock behaviour of thermal barrier coatings}

Performance of TBC systems are closely related to the methods used in production. Plasma spray and EB-PVD methods are widely used in top coat production in TBCs and applied to gas turbine blade and vanes in aviation industry. The service life and mechanic properties of TBCs are closely related to the ceramic top coat microstructure. Characteristic properties in microstructure that stem from coating method in plasma spray coatings have direct effect on thermal cycle/shock behaviour and performance of TBC systems. It is known that microstructure of coatings produced by plasma spray method consist of splats and there are pores, cracks and spaces between lamellas [12-15].

Porosity percentage of ceramic coatings produced with plasma spray method range from $\% 3$ to $\% 20$. High porosity is an advantage since it reduces the thermal conductivity of the coating. Residual stresses, which occur in YSZ coatings, stem from the thermal expansion mismatch between metal and ceramic. As the porosity in coating increases, the residual stress will decrease [50-52]. Another factor that is effective in coating performance is micro crack density. Micro cracks form as a result of rapid cooling of melted splats in plasma spray ceramic coatings. As the density of horizontal cracks on coating increases, thermal cycle/shock life of coating decreases. As a result, properties such as; porosity, horizontal and vertical cracks and elastic modulus in TBC systems are key parameters that affect thermal cycling life. It is important to keep these parameters in optimum levels in service and to identify their relationship with each other carefully, for the coating system to resist thermal cycling [53-55].

Macro cracks that form perpendicular to the substrate surface of TBC are called segmentation cracks. Coating structures with segmentation cracks have superior properties to other coating structures. Segmentation cracks are known to increase tolerance to stresses that arise from thermal expansion mismatch between substrate and coating. Segmentation cracks increase the stress tolerance of the coating and as a result, significantly decreases thermo-mechanical property differences that cause thermal stresses at substrate and coating interface. Therefore, TBC systems with segmentation cracks show a promising potential for increasing thermal cycling performance and life [56-58].

Ceramic top coats that are applied to aviation components such as turbine blade and vanes and jet engine parts by APS technique need to have high thermal cycle/shock resistance in order to stand high loading conditions. APS coatings mostly fail by spallation due to stress energy that occurs during thermal cycle process. One way to decrease the accumulation of stress is to use coatings with high porosity, because micro-cracks and porosity on coatings can absorb some of the stress. Understanding the failure mechanisms that are activated during thermal cycle/shock tests in APS coatings is only possible by investigation of stress levels. At high temperatures, tensile stresses occur as a result of thermal expansion coefficient differences and temporary temperature gradients during rapid thermal cycling between substrate and ceramic layer in APS coatings. Stress relaxation will take place during isothermal hot period and this creates compressive stress at the end of cooling from service temperature to room temperature. The increase in compressive stress will be the main reason of the increase in cracks by causing short cycle life in coatings. Besides, low shrinking stress levels before cooling will 
cause low compressive stress and thus driving force necessary for the cracks to propagate will be decreased [58-61].

EB-PVD process is a coating method, which is used to apply TBCs to gas turbine engine parts by melting the material that will be coated, evaporating under vacuum and collecting on the substrate material [15,50-52,62]. Coatings that are produced with EB-PVD method have high strain tolerance and their outer surface and TBC-BC interface are quite smooth. Since EB-PVD coatings have high strain tolerance and ability to work under high temperature oxidation conditions, their endurance under flight working conditions is quite high $[14,24,63]$. EB-PVD coating's columnar microstructure provides remarkable resistance against thermal shocks and mechanical. This enables turbine blades to be used at high pressure and temperatures. Plasma spray coatings show laminar microstructure. This situation causes cracks to form parallel to surface, which affect working life of TBCs. Coatings produced with plasma spray have 0.8-1.0 $\mathrm{W} / \mathrm{mK}$ thermal conductivity in room temperature. These values are much lower compared to EB-PVD coatings, thermal conductivity of which is $1.5-1.9 \mathrm{~W} / \mathrm{mK}$. That means APS coatings provide much better thermal insulation during service [22,64-66]. In recent years, researchers have shown great interest on above-mentioned properties of TBCs in thermal cycling in relation to prolonging service life and endurance [37,51,67-70].

\subsection{Thermal shock concept}

One of the weakest points of brittle materials like ceramics is that their thermal shock resistance is low. Thermal shock resistance changes with fracture toughness, elastic modulus, poisson's ratio, thermal expansion coefficient and thermal conductivity. Regarding these parameters, stresses that occur due to the temperature difference between centre and surface of a specimen cooled with water or heated rapidly can be found. This situation, where stresses occur under thermal shock conditions and changes that take place during thermal shock are given in Figure 5 . Here, $\Delta \mathrm{T}$ states temperature difference, $\mathrm{Tp}$ states temperature at specimen surface and $\mathrm{Tz}$ states the temperature at the centre of the specimen[17].
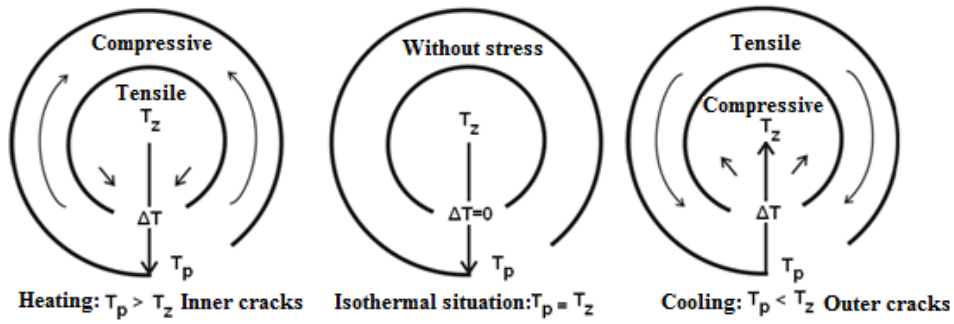

Figure 5. The representation of stress development under different thermal conditions [17].

Ceramic materials, due to their high melting temperature find use in many high temperature applications. In order for the ceramic materials used in TBC systems to resist thermal shock failure, they need to have some basic properties such as; toughness, low thermal conductivity, 
phase stability at high temperatures, high thermal expansion coefficient and low elastic modulus value [71-72].

Reliability is quite important for TBCs under service conditions. However, since they work under significant temperature fluctuations, some changes in material properties are seen. For example, under normal conditions, gas turbines run and stop repeatedly. This situation brings along degradation mechanisms such as; the thermal expansion, sintering effect and high temperature friction, and thus causes continuous change of the interior stresses in turbine blades. Accordingly, with closing or the growth of cracks, the elastic modulus value changes and this has a major impact on life of TBC under service conditions [55,73-74]. TBC systems can be used as thermal insulators due to their low thermal conductivity. Thermal stresses occur because hot section components that have TBC coating in gas turbines work under rapid thermal cycling conditions in service conditions and this makes the studies rather difficult. Because of this, thermal shock resistance plays an important role in protecting endurance under service conditions in TBCs [75-76].

TBCs fail as a result of removal or separation of coatings under high cycle conditions they are exposed to.

It is believed that the removal of ceramic components under service conditions in TBCs are affected by stresses during service as well as corrosive and erosive degradation damages and residual stress caused by coating process. The increase in thermal shock resistance of coatings that are exposed to thermal cycling can be achieved by controlling residual stresses that occur in service and increasing strain tolerance of ceramic structure. A good resistance can be achieved during thermal cycling by controlling the structural and segmentation micro cracks, and the porosity content $[23,61,77]$.

TBC systems are damaged because of various reasons but failures generally occur as a result of a combination of mechanisms. The failures can take place either in the production of TBC or can take place during service conditions. The basic failure mechanisms that limits the life of TBCs are affected by thermo-mechanic failures, chemical failures, erosion failures, oxidation of bond coating, sintering of top coat, hot erosion effect, $\mathrm{CMAS}\left(\mathrm{CaO}-\mathrm{MgO}-\mathrm{Al}_{2} \mathrm{O}_{3}-\mathrm{SiO}_{2}\right)$ attack and many other failure types. The most dominant failures mechanism seen in TBCs stems from the formation of TGO structure. A combination of these mechanism with inconsistency in thermal expansion, changes in thermal conductivity ratio and chemical interactions in the engine speed up the failure of TBCs [67,78-82]. Crack formation takes place evantually depending on the time of exposure to high temperature in thermal cycle/shock test. The most important elements that cause the formation of these cracks on TBC and TGO layer are stresses that occur as a result of TGO growth, phase transformations in bond coat, changes in bond coat during thermal cycle and sintering of TBC. Once the cracks form, they propagate and coalesce and result in failure of the coating [83-85].

The formation mechanism of thermo-mechanical stresses change depending on the thermal conditions that TBC is exposed to. If the thermal conditions are isothermal, the mechanism is generally about TGO's growth. But if the TBC is exposed to thermal cycle, the mechanism will be rather related to shrinkage of TGO during cooling. These two situations can be effective in the 
formation of thermo-mechanic stresses but it should not be ignored that one can dominate the other in some cases. For example; TBCs that work at high temperatures and for long service times are used in gas turbines for energy production on the ground. In this case, isothermal mechanisms become effective and expansion and shrinkage occur when the turbine stops. Consequently, low number of thermal cycle and longer isothermal heating take place in this type of turbines and as a result of this, failure occurs when TGO reaches approximately 5-15 $\mu \mathrm{m}$ thickness. In turbine parts, failures due to thermal expansion mismatchinduced by TGOlayer and failures due to TGOlayergrow tharedominant. However, in theturbines thatare used inaviation sector where the thermal cycling number is important, isothermal heating is not dominant and failure occur due to thermal cycles when TGO is almost $1-5 \mu$ m during service $[12,86]$.

Thermal expansion coefficient mismatch between substrate material and TBC has an important role on the thermal cycle/shock life of TBCs. The rate of mismatch between superalloy substrate material and top coat affects elastic strain energy that is stored during cooling from working temperature. High amount of strain energy causes early removal/breaking of coating as a result of cycling [84,87-88].

Superalloy substrate materials used in TBCs have an effect on thermal cycle life of TBC system. The elements can diffuse from superalloy to bond coat and this diffusion between substrate and bond coat increase or decrease the life depending on the element. For example, as a result of hafnium element diffusion from substrate to bond coat, the adherence of TGO is increased and thus TBC life increases. As a contrary case, the diffusion of tantalum element to bond coat affects the TGO composition and oxides other than alumina may form in TGO structure which results in a reduction of TBC life [84,89-90].

The rapid heating and cooling of coating during thermal cycle inevitably increase the damage on oxide layer. Coating endurance against thermal cycle/shock and degradation can change depending on adherence of coating layers and oxide layer that occurs on coating surface [91-92]. There are three basic reasons of oxide-based removal of coating after thermal shock [92-93]. The first of these reasons reported in the literature is the stress that occurs based on the growth of oxide layer depending on the exposure of the specimen to high temperatures for a long time and removal/breaking and spallation that happen as a result of this. Another factor is the thermal expansion that occur because of the temperature gradient on oxide layer which is a result of rapid heating and cooling. The last factor is the thermal expansion coefficient difference between oxide and coating that take place with the growth of oxide layer. At the end of rapid cooling, compressive stress occur on oxide layer, which has a lower thermal expansion coefficient than substrate material. Stress case changes in rapid heating and tensile stress arise on oxide layer.

Deformations may take place because of the rapid cooling from high temperatures and tensile stress that is generated at the coating/oxide interface [12,92-93].

\subsection{Thermal cycle/shock tests for TBCs}

For development of TBCs and evaluating the quality of the coatings, the aviation and industrial gas turbine manufacturers apply various thermal cycle/shock tests. TBCs are used usually under 
high thermal loads in gas turbine parts such as; turbine blades and vanes. There has been no identified method that would provide advantage in comparing the results in this subject. The reason of this is the difficulty of finding a test method that can completely reflect the working conditions.Today, systemsthataredevelopedby theengineproducerstosimulatetherealthermal conditionsin theengines are burnerheating thermal shock test unit(burner rig system), jetengine thermal shock test unit (JETS) and furnace cycle tests. By creating high temperature gradients in ceramics with burner thermal shock test, stresses that affect the integrity of ceramic coating are introduced. Generally disk shaped specimens are used in this test system. The test system is based on cooling of the specimen after heating by a flame where propane and oxygen gases are used together. Since burner heating thermal shock test unit is an expensive system, JETS test has been developed as an economic alternative method for the gradient tests. In JETS test burner equipment is used to create a wide thermal gradient along the TBC and thermo-mechanic stresses on the surface. In furnace cycle oxidation test (FCT) method that is used widely in aviation applications, stresses occur mostly as a result of TGO growth and on ceramic/bond coat.[16-20,68]. A depiction of heating and cooling cycles in burner heating thermal shock unit and a photograph of heating during thermal shock test system are shown in Figure 6 [94-95].

In the experiments carried out in burner- thermal shock test unit, coated surfaces of the samples, are heated while the bare surfaces are cooled with pressured air. Oxygen $\backslash$ natural gas and propane are used as combustive gases. Forming a heat gradient in the sample is aimed and generally for gas turbine practices these types of systems are optimised. The samples that are used in the experiments are generally disc shaped and have a thickness between 2.5-3.0 $\mathrm{mm}$. In burner-thermal shock test system, surface temperature of the specimens are measured by pyrometer, while temperature variation of the substrate material is measured via a thermocouple that passes through centre. Surface temperatures of the coated side of the sample change between 1200 and $1500{ }^{\circ} \mathrm{C}$ in accordance with a typical coated turbine component. In literature, thermal cycle durations generally consist of 5 minutes heating and 2 minutes cooling periods. Thermal cycle life of coatings change according to testing temperature and waiting time. Failure criteria in the tests, are based on visual inspection of the coating surface for damages or loss of the coating. In general, a total surface area of coating loss ranging from 10 to $20 \%$ is considered as the criterion for failure. The failure mechanisms effective in this system is mainly related to TGO growth at low temperatures and occur at TBC surface at temperatures above $1300^{\circ} \mathrm{C}[16-19,94-99]$.

The other test method used in evaluation of thermal cycle/shock properties of TBCs is the furnace cycle test. Furnace cycle test better reflect the actual engine conditions. Because this process not only causes cyclic stresses in $\mathrm{TBC}$, but also give rise to a degradation of the bond coating as a result of severe oxidation. In test conditions, as a result of prolonged exposure of TBC to high temperature, oxidation of bond coating takes place. In addition, design limit and performances such as complete failure and depletion of bond coating can be observed with the furnace cycle tests. In this test system, TBC samples generally are subjected to the oxidation between the temperature range $1000-1200{ }^{\circ} \mathrm{C}$, then subjected to cyclic cooling at room temperature. Thermal changes that occur in TBC, take place during the heating and cooling processes. Heating of the system is carried out in the furnace while air-cooling is implemented 
with the aid of a compressor or fan. A cycle for aircraft engine component consists of 1 hour period, 45-50 minutes of which is in elevated temperatures and 10-15 minutes is spent for cooling. However for industrial gas turbine applications, in order to extend the duration of exposure to high temperature, cycles of 24 hours is typically used and a period of 23 hours of the cycle takes place in elevated temperatures $\left(1080^{\circ} \mathrm{C}-1135^{\circ} \mathrm{C}\right)$ while a period of 1 hour is spared for cooling at room temperature. The samples used in these tests are usually disc shaped and of $25.4 \mathrm{~mm}$ diameter and criterion for failure is again $10-20 \%$ spallation of coated surface. [18,100-102]. FCT test setup for TBC system characterisation can be seen in Figure 7. [18].

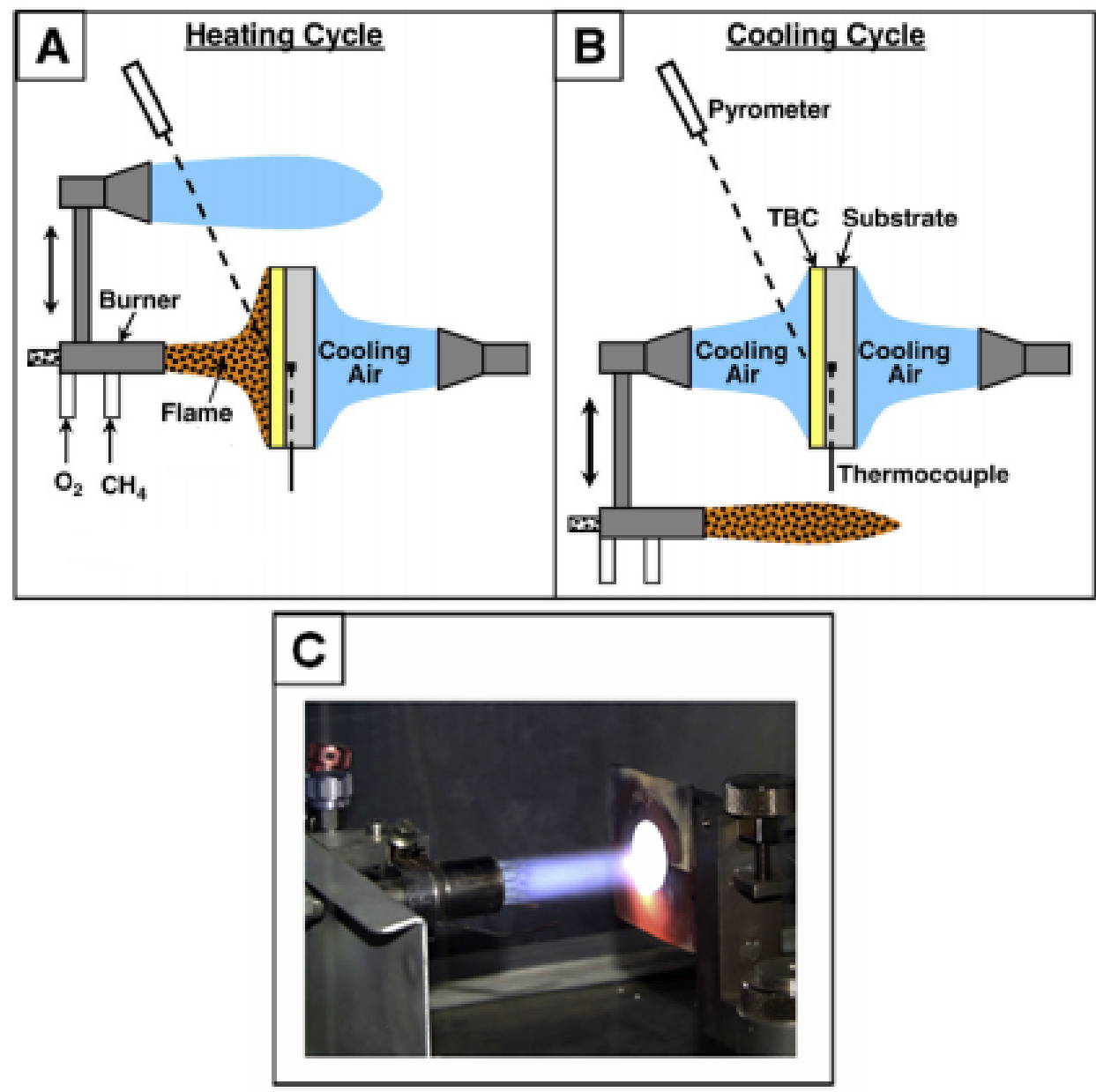

Figure 6. An illustration of thermal shock test device; a) schematic diagram that shows the system heating cycle; b) schematic diagram that shows the system cooling cycle; c) heating cycle photograph of a standard test specimen in thermal cycle/shock equipment [94-95]. 

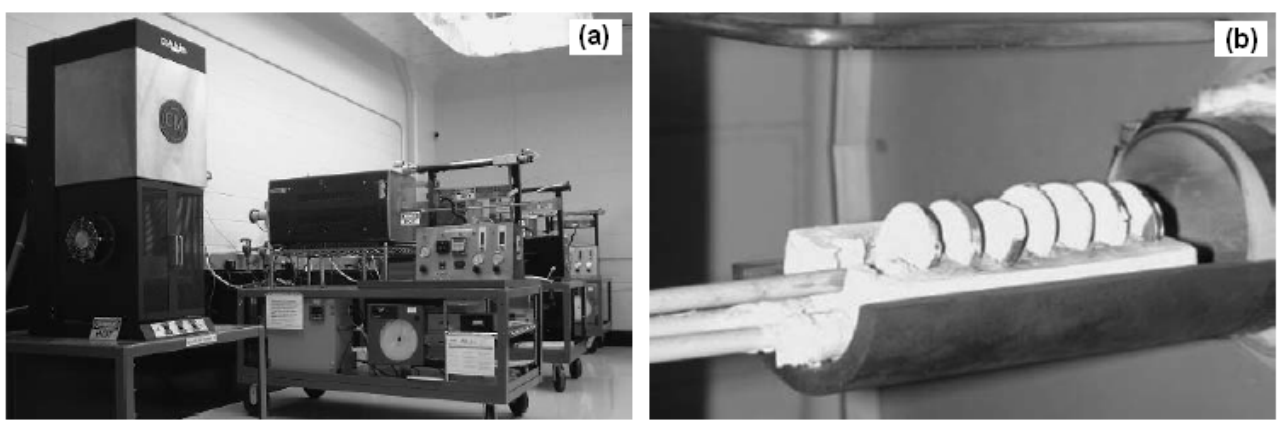

Figure 7. Furnace cycle test system; (a) FCT setup for TBC/bond coat system (b) Samples and sample holder representing the system [18].

In a study by Vaßen et al., NiCOCrAIY bond coats produced by VPS method and TBC systems with YSZ top coat produced by APS method are exposed to thermal cycle and furnace tests. Failure on the coating of the samples as a result of these tests are shown in Figure 8 [103].
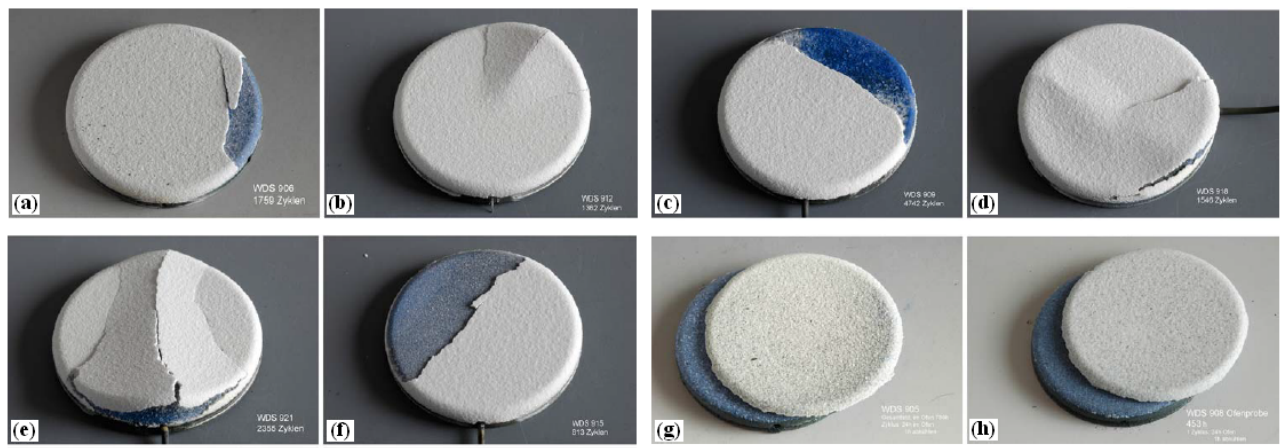

Figure 8. Macro images of TBCs produced with different porosity and micro cracks contents after thermal cycle/shock and furnace test; (a)-(d) After burner thermal shock test, (g)-(h) After furnace cycle test [103].

In this study, different TBC systems which are standard, with a high density of micro-cracks, with a content of thick and low porosity and high porosity and with segmentation cracks were investigated by being subjected to burner heating thermal shock and furnace cycle test. In burner thermal shock testing, 5 minutes heating and 2 minutes cooling regimen was used and the sample's surface temperature was kept at $1250^{\circ} \mathrm{C}$. The furnace cycle test was conducted at $1100^{\circ} \mathrm{C}$ with 24 hours heating period at furnace and 1 hour cooling period outside the furnace at room temperature. As a result of studies, it was observed that TBC systems' thermal cycle lives have decreased depending on these parameters in the cycle life of coatings as a result of adverse influence such as TGO thickness which happens and increases on the coating interface, rising temperature of coating surface, sintering effects, stresses resulting from the mixed oxide 
coatings [103]. In TBC systems, after the oxidation and thermal cycle/shock test, distortion occurs depending on the type of the formation of damage on the sample's surface.

In aerospace applications, the other test method used to determine the thermal shock features of TBCs is JETS method. JETS test is very suitable to provide data on the performance rating on the ceramic itself, but as it does not damage bond coat it does not distinguish errors related to bond coat very well. As a result of high temperature gradients in the ceramic layer with JETS test, weak spots in the ceramic interfaces can be revealed [18]. In Figure 9, a JETS test set up which is used for characterisation of TBC systems can be observed[68].

By creating a large temperature gradient over the TBCs with JETS test, surface temperature rise up to $1400^{\circ} \mathrm{C}$ and as a result of high temperature, sintering effect act on ceramic top coat. In this test, the main stresses occur thermo-mechanically at the interface of the ceramic and bond coat.

Due to the high temperature gradient within the ceramic layer, TBC/BC interface is oxidised at a small rate. This test is quite fast and the results can be achieved avaregely in 2 days. Similar to the other thermal cycle/shock test, the sample geometry is also disc shaped and has a diameter of $25.4 \mathrm{~mm}$. Right after the heating starts; the samples are cooled by a jet of nitrogen. Nitrogen jet provides the maximum accessible temperature gradient during cooling. In this test, a typical cycle consists of 20 seconds of heating period, 20 seconds of cooling period with nitrogen gas and 40 seconds of waiting period in open atmosphere. [18,68].

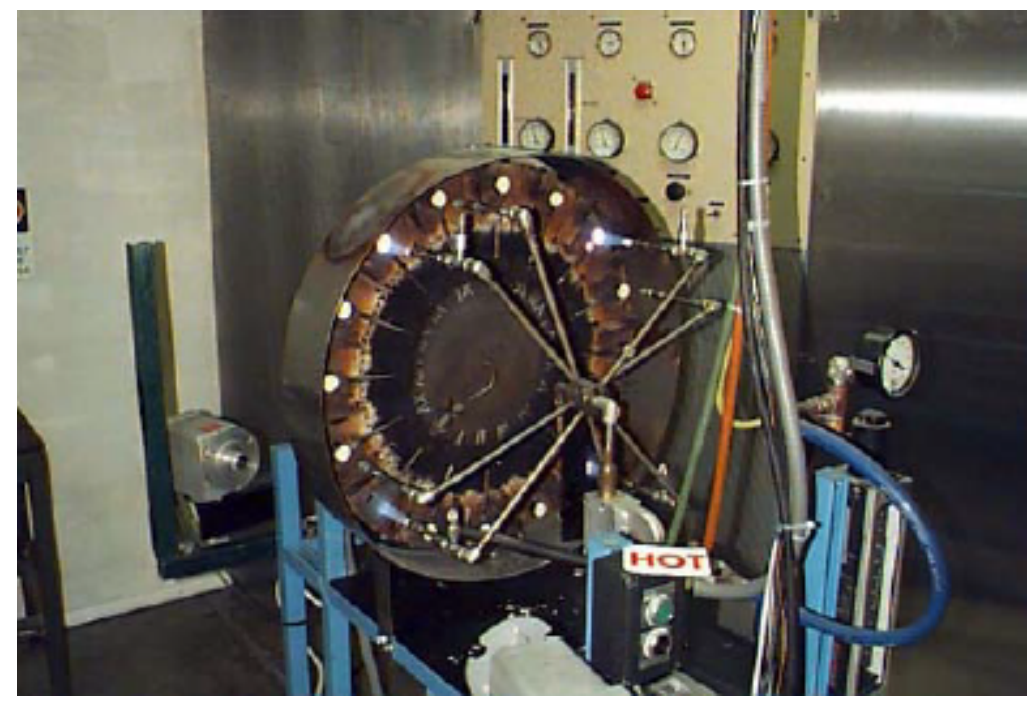

Figure 9. Wide JETS setup with four heating and cooling station [68]. 


\section{Summary}

In the literature, there are many studies, which are carried out in different cycle tests (with different heating, cooling-holding periods) in different environments (air, water) and systems (heating with burners, furnace cycle tests, JETS test etc.) to determine the thermal cycle/shock behaviour of TBCs. Scientific and industrial institutions continue research, development and studies by simulating real thermal conditions in engines, for investigation of the failure mechanisms and TGO growth behaviours. In this study, TBC systems are introduced and thermal cycle/shock behaviour of TBCs under service conditions and the thermal cycle/shock tests used for evaluation of TBC systems are explained.

\section{Acknowledgements}

This work partially supported by The Scientific and Technological Research Council of Turkey (TUBITAK, 111M265).

\section{Author details}

Abdullah Cahit Karaoglanli ${ }^{1}$, Kazuhiro Ogawa ${ }^{2}$, Ahmet Türk ${ }^{3}$ and Ismail Ozdemir ${ }^{4}$

1 Dept. of Metalurgical and Materials Eng., Bartin University,Bartin, Turkey

2 Fracture \& Reliability Research Institute, Tohoku University, Sendai, Japan

3 Dept. of Metalurgical and Materials Eng., Sakarya University,Sakarya, Turkey

4 Dept. Of Materials Science and Eng., Izmir Katip Celebi University, Izmir, Turkey

\section{References}

[1] Mobarra R., Jafari A.H., Karaminezhaad M., Hot corrosion behavior of MCrAlY coatings on In 738LC, Surf.Coat.Tech., 2006, 201, 2202-2207.

[2] Nijdam T.J., Sloof W.G., Combined pre-annealing and pre-oxidation treatment for the processing of thermal barrier coatings on NiCoCrAlY coatings, Surf.Coat.Tech., 2006. 201, 3894-3900.

[3] Li Y., Li C-J., Zhang Q., Xing K., Yang G-J., Effect of surface morphology of MCrAlY bond coats on isothermal oxidation behavior, International Thermal Spray Conference, ITSC 2010, DVS-ASM, Raffles City, Singapore, 2010, 491-497. 
[4] Xie D., Xiong Y., Wang F., Effect of an enamel coating on the oxidation and hot corrosion behavior of an HVOF sprayed CoNiCrAlY coatings, Oxidation of Metals, 2003, 59, 503-516.

[5] Yuan F.H., Chen Z.X., Huang Z.W., Wang Z.G., Zhu S.J., Oxidation behavior of thermal barrier coatings with HVOF and detonation sprayed NiCoCrAlY bond coats, Corrosion Science, 2008, 50,1608-1617.

[6] Schloesser J., Baker M., Rosler J., Thermal barrier coatings for rocket engines, International Thermal Spray Conference, ITSC 2011, DVS, Hamburg, Germany, 2011, 952-955.

[7] Lampke T., El-Mahallawy N., Grund T., El-Araby I., Karaoglanli A.C., Effect of bond coat material and heat treatment on adhesion strength and characteristics of Thermal Barrier Coating system with CGDS, HVOF and APS techniques, International Thermal Spray Conference, ITSC 2011, DVS, Hamburg, Germany, 2011, 956-959.

[8] Arai M., Suidzu T., Development of porous ceramic coating for high-efficiency cooling system, International Thermal Spray Conference, ITSC 2011, DVS, Hamburg, Germany, 2011, 960-965.

[9] Takahashi S., Hirano N., Kojima Y., Harada Y., Kawasaki A., Ono F., Thermal shock resistance of plasma-sprayed Thermal Barrier Coatings, International Thermal Spray Conference, ITSC 2011, DVS, Hamburg, Germany, 2011, 1025-1029.

[10] Li C.J., Li Y., Yang G.J., Li C.X., A novel plasma-sprayed durable thermal barrier coating with the well-bonded YSZ interlayer between porous YSZ and bond coat, International Thermal Spray Conference, ITSC 2011, DVS, Hamburg, Germany, 2011, 1234-1240.

[11] Karaoglanli A.C., Lampke T., Grund T., Ak Azem F., Ozdemir I., Turk A., Ustel F., Study of oxidation behavior of TBCs with APS and HVOF CoNiCrAlY bond coatings, International Thermal Spray Conference, ITSC 2011, DVS, Hamburg, Germany, 2011, 942-947.

[12] Evans A.G., Mumma D.R., Hutchinson J.W., Meierc G.H., Pettit F.S., Mechanisms controlling the durability of thermal barrier coatings, Progress in Materials Science, 2001, 46 (5), 505-55.

[13] Sridharana S., Xiea L., Jordan E.H., Gella M., Murphy K.S., Damage evolution in an electron beam physical vapor deposited thermal barrier coating as a function of cycle temperature and time, Materials Science and Engineering A, 2005, 393 (1-2), 51- 62.

[14] Bernier J., Evolution and Characterization of Partially Stabilized Zirconia (7wt\% $\mathrm{Y}_{2} \mathrm{O}_{3}$ ), Thermal Barrier Coatings Deposited by Electron Beam Physical Vapor Deposition, Master Thesis, Worcester Polytechnic Institute, May 18, 2001. 
[15] Limarga A.M., Clarke D.R., Characterization of Electron Beam Physical Vapor Deposited Thermal Barrier Coatings Using Diffuse Optical Reflectance, Int. J. Appl. Ceram. Technol., 2009, 6 (3), 400-409.

[16] Vaßen R., CERNUSCHI F., RIZZI G., SCRIVANI A., MARKOCSAN N., OSTERGREN L., KLOOSTERMAN A., MEVREL R., FEIST, J., NICHOLLS J., Recent Activities in the Field of Thermal Barrier Coatings Including Burner Rig Testing in the European Union, Advanced Engineering Materials, 2008, 10, No. 10, 907-921.

[17] Kara,I, E., TBK Kaplamaların Termal Şok Özelliklerinin İncelenmesi, Master Thesis, Sakarya University, Metalurgical and Materials Engineering Department, (in Turkish), 2008.

[18] Bolcavage A., Feuerstein A., Foster J., Moore P., Thermal Shock Testing of Thermal Barrier Coating/Bondcoat Systems, Journal of Materials Engineering and Performance, 2004, Vol: 13(4), 389-397.

[19] Traeger F., Vaßen, R., Rauwald K.H., Stover D.., Thermal Cycling Setup for Testing Thermal Barrier Coatings, Advanced Engineering Materials, 2003, Vol: 5 (6), 429-432.

[20] Thompson J.A., Clyne T.W., The Effect Of Heat Treatment On The Stiffness Of Zirconia Top Coats in Plasma Sprayed Zirconia Top Coats in Plasma-Sprayed TBCs, Acta mater., 2001, 49, 1565-1575.

[21] Feuerstein A., Knapp J., Taylor T., Ashary V, Bolcavage A., Hitchman N., Technical and Economical Aspects of Current Thermal Barrier Coating Systems for Gas Turbine Engines by Thermal Spray and EB-PVD: A Review, Journal of Thermal Spray Technology, 2008, Vol: 17, 199-213.

[22] Bose S., High Temperature Coatings, Butterworth-Heinemann, Elsevier, ISBN-13:978-0-7506-8252-7, 2007.

[23] Koolloos M.F.J., Behaviour of low porosity microcracked thermal barrier coatings under Thermal Loading, PHd. Thesis, Technische Universiteit Eindhoven, NLR, Nedherland, March, 1-168, 2001.

[24] Hass D.D., Thermal Barrier Coatings via Directed Vapor Deposition, Department of Materials Science and Engineering, Vol. PhD. Charlottesville, VA: University of Virginia, 1-256, 2001.

[25] Jones R.L, Some aspects of the hot corrosion of thermal barrier coatings, Journal of Thermal Spray Technology, 1997, 6 (1), 77-84.

[26] Patrick R., Development of Conventional and Nanocrystalline Bond Coats by Cold Gas Dynamic Spraying for Aerospace Thermal Barrier Coatings, PhD Theses, University of Ottowas, Ottowa Ontario Canada, 1-227, July 19, 2010.

[27] ASM Handbook: Volume 5: Surface Engineering (ASM Handbook), ISBN-13: 978-0871703842, December 1, 1994. 
[28] Chen W.R., Wu X., Marple B.R., Nagy D.R., Patnaik P.C., TGO growth behaviour in TBCs with APS and HVOF bond coats, Surf.Coat.Tech., 202, 2677-2683, 2008.

[29] Donachie M.J., Donachie S.J., Superalloys, A Technical Guide, Second Edition, ASM International, ISBN: 0-87170-749-7, 2002.

[30] Saeidi S., Microstructure, Oxidation \& Mechanical Properties of As-sprayed and Annealed HVOF \& VPS CoNiCrAlY Coatings, PhD Thesis, University of Nottingham, December 2010.

[31] Roberts T., The Structure and Stability of High Temperature Intermetallic Phases for Application within Coating Systems, PhD Thesis, Cranfield University, November 2009.

[32] Eriksson R., High-temperature degradation of plasma sprayed thermal barrier coating systems, PhD thesis, Linköping University, April 2011, ISBN 978-91-7393-165-6, Linköping Sweden, April 252011.

[33] Yoshiba M., Abe K., Aranami T., Harada Y., High-Temperature Oxidation and Hot Corrosion Behavior of Two Kinds of Thermal Barrier Coating Systems for Advanced Gas Turbines, Journal of Thermal Spray Technology, 1996, Vol 5 (No. 3), 259-268.

[34] Taylor T.A., Walsh P.N., Thermal expansion of MCrAlY alloys, Surf.Coat.Tech., 2004, 177-178, 24-31.

[35] Fox A.C., Clyne T.W., Oxygen Transport by Gas Permeation through the Zirconia Layer in Plasma Sprayed Thermal Barrier Coatings, Surf. Coat. Tech., 2004, 184, 311-321.

[36] Richer P., Yandouzi M., Beauvais L., Jodoin B., Oxidation behaviour of CoNiCrAlY bond coats produced by plasma, HVOF and cold gas dynamic spraying, Surf.Coat.Tech., 2010, 204, 3962-3974.

[37] Li Y., Li C.J., Zhang Q., Yang G.J., Li C.X., Influence of TGO composition on the thermal shock lifetime of thermal barrier coatings with cold-sprayed MCrAlY bond coat, Journal of Thermal Spray Technology, 2010, 19 (1-2), 168-177.

[38] Tang F., Ajdelsztajn L., Kim G.E., Provenzano V., Schoenung J.M., Effects of Surface Oxidation during HVOF Processing on the Primary Stage Oxidation of a CoNiCrAlY Coating, Surf.Coat.Tech. , 2004, 185, 228-233.

[39] Dalkilic, S., Bir Termal Bariyer Kaplama Sisteminin Yorulma Davranışının İncelenmesi, PhD Thesis, Anadolu University,(In Turkish), March 2007.

[40] Koolloos M.F.J., Houben J.M., Behavior of Plasma-Sprayed Thermal Barrier Coatings during Thermal Cycling and the Effect of a Preoxidized NiCrAIY Bond Coat, Journal of Thermal Spray Technology, 2000, Volume 9(1), 49-58.

[41] Cao X.Q., Vassen R., Stoever D., Ceramic materials for thermal barrier coatings, Journal of the European Ceramic Society, 2004, 24, 1-10. 
[42] Vanvalzah J.R., Eaton H.E., Cooling Rate Effects on the Tetragonal to Monoclinic Phase Transformation in Aged Plasma-Sprayed Yttria Partially Stabilized Zirconia, Surf.Coat.Tech., 1991, Vol 46, 289-300.

[43] Pawlowski L., The Science and Engineering of Thermal Spray Coatings, John Wiley \& Sons, 2nd Edition, 67-165, 2008.

[44] Ballard J.D., Davenport J., Lewis C., Nelson W., Doremus R.H., Schadler L.S., Phase Stability of Thermal Barrier Coatings Made From 8 wt.\% Yttria Stabilized Zirconia: A Technical Note, Journal of Thermal Spray Technology, 2003, Vol 12(1), 34-37.

[45] Clyne T.W., Gill S.C., Residual Stresses in Thermal Spray Coatings and their Effect on Interfacial Adhesion- A Review of Recent Work, Journal of Thermal Spray Technology, 1996, Vol:5, 401-418.

[46] Chraska P., Dubsky J., Neufuss K., Pisacka J., Alumina-Base Plasma-Sprayed Materials Part I: Phase Stability of Alumina and Alumina-Chromia, Journal of Thermal Spray Technology, 1997, Vol 6 (3), 320-326.

[47] M. Saremi, A. Afrasiabi, A. Kobayashi, Microstructural analysis of YSZ and YSZ/ $\mathrm{Al}_{2} \mathrm{O}_{3}$ plasma sprayed thermal barrier coatings after high temperature oxidation, Surf.Coat.Tech., 2008, 202, 3233-3238.

[48] Miller R.A., Thermal Barrier Coatings for Aircraft Engines: History and Directions, Journal of Thermal Spray Technology, 1997, Vol 6(1), 35-42.

[49] Levi C.G., Emerging materials and processes for thermal barrier systems, Current Opinion in Solid State and Materials Science, 2004, 8, 77-91.

[50] Erk K.A., Deschaseaux C., Trice R.W., Grain-Boundary Grooving of Plasma-Sprayed Yttria-Stabilized Zirconia Thermal Barrier Coatings, J. American Ceram. Soc., 2006, 89 (5), 1673-1678.

[51] Haynes J.A., Ferber M.K., Porte W.D., Thermal Cycling Behavior of Plasma-Sprayed Thermal Barrier Coatings with Various MCrAIX Bond Coats, Journal of Thermal Spray Technology, 2000, Vol 9(1), 38-48.

[52] Polat A., Sarikaya O., Celik E., Effects of porosity on thermal loadings of functionally graded $\mathrm{Y}_{2} \mathrm{O}_{3}-\mathrm{ZrO}_{2} / \mathrm{NiCoCrAlY}$ coatings, Materials and Design, 2002, 23, 641-644.

[53] Vaßen R., Traeger F., Stover D., Correlation Between Spraying Conditions and Microcrack Density and Their Influence on Thermal Cycling Life of Thermal Barrier Coatings, Journal of Thermal Spray Technology, 2004, Vol 13(3), 396-404.

[54] Grunling H.W., Mannsmann W., Plasma sprayed thermal barrier coatings for industrial gas turbines: morphology, Processing and properties, Journal De Physique IV Colloque C7, supplement au Journal de Physique 111, 1993, Vol 3, 903-912. 
[55] Siebert B., Funke C., Vaßen R., Stover D., Changes in porosity and Young's Modulus due to sintering of plasma sprayed thermal barrier coatings, Journal of Materials Processing Technology, 1999, 92-93, 217-223.

[56] Guo H.B., Vaßen R., Stover D., Atmospheric plasma sprayed thick thermal barrier coatings with high segmentation crack density, Surf.Coat.Tech., 2004, 186, 353-363.

[57] Guo H., Murakami H., Kuroda S., Thermal Cycling Behavior of Plasma Sprayed Segmented Thermal Barrier Coatings, Materials Transactions, 2006, Vol 47 (2), 306-309.

[58] Karger M., Vaßen R., Stover D., Atmospheric plasma sprayed thermal barrier coatings with high segmentation crack densities: Spraying process, microstructure and thermal cycling behavior, Surf.Coat.Tech., 206, 16-23, 2011.

[59] Beele, W., Marijnissen G., Liehot A., The evolution of thermal barrier coatings-status and upcoming solutions for today's key issues, Surface and Coatings Technology, 1999, Vol 120-121, 61-67.

[60] Teixeria V., Andritschky M., Gruhn H., Mallener W., Buchkremer H.P., Stover D., Failure of Physical Vapor Deposition/Plasma-Sprayed Thermal Barrier Coatings during Thermal Cycling, Journal of Thermal Spray Technology, 2000, Vol 9(2), 191-197.

[61] Hengbei Z., Zhuo Y., Haydn N.G. Wadley, The influence of coating compliance on the delamination of thermal barrier coatings, Surf.Coat.Tech., 2010, 204, 2432-2441.

[62] Suzuki K., Shobu T., Tanaka K., Residual Stresses of EB-PVD thermal barrier coatings exposed to high temperature, International Centre for Diffraction Data, ISSN 1097-0002, 2009, 537-544.

[63] Kumar S., Cocks A.C.F., Sintering and mud cracking in EB-PVD thermal barrier coatings, Journal of the Mechanics and Physics of Solids, 2012, Vol 60 (4), 723-749.

[64] Guo H., Gong S., Khor K.A., XU H., Effect of thermal exposure on the microstructure and properties of EB-PVD gradient thermal barrier coatings, Surf.Coat.Tech., 2003, $168,23-29$.

[65] Anderson P.S., Wang X., Xiao P., Impedance spectroscopy study of plasma sprayed and EB-PVD thermal barrier coatings, Surf.Coat.Tech., 2004, 185-1, 106-119.

[66] Nicholls J.R., Lawson K.J., Johnstone A., Rickerby D.S., Methods to reduce the thermal conductivity of EB-PVD TBCs, Surf.Coat.Tech., 2002, 151-152, 383-391.

[67] Liu J., Effects of bond coat surface preparation on thermal cycling lifetime and failure characteristic of thermal barrier coatings, Master of Science Thesis, Department of Mechanical, Materials, and Aerospace Engineering, University of Central Florida, Summer Term, 2004.

[68] Helminiak M.A., Factors Affecting The Lifetime Of Thick Air Plasma Sprayed Thermal Barrier Coatings, Master Thesis, University of Pittsburgh, March 18, 2010. 
[69] Postolenko V., Failure Mechanisms of Thermal Barrier Coatings for High Temperature Gas Turbine Components under Cyclic Thermal Loading, PhD Thesis, Von der Fakultät für Georessourcen und Materialtechnik der Rheinisch -Westfälischen Technischen Hochschule Aachen, November, 2008.

[70] Mumm D.R., Watanabe M., Evans A.G., Pfaendtner J.A., The influence of test method on failure mechanisms and durability of a thermal barrier system, Acta Materialia, 2004, 52, 1123-1131.

[71] Han J.C., Wang B.L., Thermal shock resistance of ceramics with temperature-dependent material properties at elevated temperature, Acta Materiala, 2011, 59, 1373-1382.

[72] Girolama G.D., Marra F., Blasi C., Serra E., Valente T., Microstructure, mechanical properties and thermal shock resistance of plasma sprayed nanostructured zirconia coatings, Ceramics International, 2011, 37, 2711-2717.

[73] Fry A.T., Banks P.J., Nunn J., Brown J.L., Comparison of the Thermal Cycling Performance of Thermal Barrier Coatings under Isothermal and Heat Flux Conditions, Materials Science Forum, 2008, Vol 595-598, 77-85.

[74] Balint D.S., Hutchinson J.W., An analytical model of rumplingin thermal barrier coatings Journal of the Mechanics and Physics of solids, 2005, 53, 949-973.

[75] Yanar N.M., The failure of therma barrier coatings at elevated temperatures, $\mathrm{PhD}$ thesis, University of Pittsburgh, 2004.

[76] Li M., Sun X., Hu W., Guan H., Thermal shock behavior of EB-PVD thermal barrier coatings, Surf.Coat.Tech., 2007, 201, 7387-7391.

[77] Khan A.N., Lu J., Behavior of air plasma sprayed thermal barrier coatings, subject to intense thermal cycling, Surf.Coat.Tech., 2003, 166, 37-43.

[78] Verbeek A.T.J., Plasma sprayed thermal barrier coatings: Production, characterization and testing, PhD Thesis, Technische Universiteit Eindhoven,1992.

[79] Aygun A., Novel Thermal Barrier Coatings(TBCs) that are resistant to high temperature attack by $\mathrm{CaO}-\mathrm{MgO}-\mathrm{Al}_{2} \mathrm{O}_{3}-\mathrm{SiO}_{2}$ (CMAS) glassy deposits, $\mathrm{PhD}$ thesis, The Ohio State University, 2008.

[80] Evans A.G., Fleck N.A., Faulhaber S., Vermaak N., Maloney M., Daroli R., Scaling laws governing the erosion and impact resistance of thermal barrier coatings, Wear, 2006, 260, 886-894.

[81] Wellman R.G., Nicholls J.R., Erosion, corrosion and erosion-corrosion of EB PVD thermal barrier coatings, Tribology International, 2008, 41 (7), 657-662.

[82] Mao W.G., Zhou Y.C., Yang L., Yu X.H., Modeling of residual stresses variation with thermal cycling in thermal barrier coatings, Mechanics of Materials, 2006, 38, 1118-1127. 
[83] Vaßen R., Kerkhoff G., Stover D., Development of a micromechanical life prediction model for plasma sprayed thermal barrier coatings, Materials Science and Engineering $\mathrm{A}, 2001,303,100-109$.

[84] Yanar N.M., Helminiak M., Meier G.H., Pettit F.S., Comparison of the Failures during Cyclic Oxidation of Yttria-Stabilized (7 to 8 Weight Percent) Zirconia Thermal Barrier Coatings Fabricated via Electron Beam Physical Vapor Deposition and Air Plasma Spray, Metallurgical and Materials Transactions A, 2011, Vol 42, 905-921.

[85] Guo H., Murakami H., Kuroda S., Effects of Heat Treatment on Microstructures and Physical Properties of Segmented Thermal Barrier Coatings Materials Transactions, 2005, Vol. 46, No. 8, 1775-1778.

[86] Wright P.K., Evans A.G., Mechanisms governing the performance of thermal barrier coatings, Current Opinion in Solid State and Materials Science, 1999, 4, 255-265.

[87] Anderson A., An Investigation Of the Thermal Shock Behavior Of Thermal Barrier Coatings, International Journal of Engineering Science and Technology, 2011, Vol 3 (11), 8154-8158.

[88] Kim J.H., Kim M.C., Park C.G., Evaluation of functionally graded thermal barrier coatings fabricated by detonation gun spray technique, Surf.Coat.Tech., 2003, 168, 275-280.

[89] Murakami H., Tetsuro Y., Satoshi S., Process Dependence of Ir-Based Bond Coatings, Materials Transactions, 2004, Vol 45 (9), 2886-2890.

[90] Peng H., Guo H., He J., Gong S., Cyclic oxidation and diffusion barrier behaviors of oxides dispersed NiCoCrAlY Coatings, Journal of Alloys and Compounds, 2010, 502, 411-416.

[91] Bacos M.P., Dorvaux J.M., Lavigne O., Mevrel R., Poulain M., Rio C., Vidal Setif M.H., Performance and Degradation Mechanisms of Thermal Barrier Coatings for Turbine Blades: a Review of Onera Activities, Journal Aerospace Lab, 2011, Issue 3, $1-11$.

[92] Mohammadi M., Javadpour S., Kobayashi A., Jahromi S.A.J., Shirvani K., Thermal shock properties and microstructure investigation of LVPS and HVOF-CoNiCrAlYSi coatings on the IN738LC superalloy, Vacuum, 2012, doi:10.1016/j.vacuum. 2012.02.003, 1-6.

[93] Wang Q.M., Tang Y.J., Guo M.H., Ke P.L., Gong J., Sun C., Wen L.S., Thermal shock cycling behavior of NiCoCrAlYSiB coatings on Ni-base superalloys I. Accelerated oxidation attack, Materials Science and Engineering A, 2005, 406, 337-349.

[94] Steinke T., Sebold D., Mack D.E., Vaßen R., Stover D., A novel test approach for plasma-sprayed coatings tested simultaneously under CMAS and thermal gradient cycling conditions, Surf.Coat.Tech., 2010, 205 7, 2287-2295. 
[95] Drexler J.M., Aygun A., Li D., Vaßen R., Steinke T., Padture N.P., Thermal-gradient testing of thermal barrier coatings under simultaneous attack by molten glassy deposits and its mitigation, Surf.Coat.Tech., 2010, 204, 2683-2688.

[96] Braue W., Mechnich P., Recession of an EB-PVD YSZ Coated Turbine Blade by $\mathrm{CaSO}_{4}$ and Fe, Ti-Rich CMAS-Type Deposits, J. Am. Ceram. Soc., 2011, 94 (12), 4483-4489.

[97] Tong C., Ji-Jie W., Ren-Guo G., Li-Qing C., Gumming Q., Microstructures and Properties of Thermal Barrier Coatings Plasma-Sprayed by Nanostructured Zirconia, Journal of Iron and Steel Research, International, 2007, Vol 12 (5), 116-120.

[98] Wu J., Guo H.B., Zhou L., Wang L., Gong S.K., Microstructure and Thermal Properties of Plasma Sprayed Thermal Barrier Coatings from Nanostructured YSZ, Journal of Thermal Spray Technology, 2010, Vol 19 (6), 1186-1194.

[99] Ma W., Dong H., Guo H., Gong S., Zheng X., Thermal cycling behavior of $\mathrm{La}_{2} \mathrm{Ce}_{2} \mathrm{O}_{7} / 8 \mathrm{YSZ}$ double-ceramic-layer thermal barrier coatings prepared by atmospheric plasma spraying, Surf.Coat.Tech., 2010, 204, 3366-3370.

[100] Spitsberg I.T., Mumm D.R., Evans A.G., On the failure mechanisms of thermal barrier coatings with diffusion aluminide bond coating, Materials Science and Engineering:A, 2005, Vol 394 (1-2), 176-191.

[101] Tolpygo V.K., Clarke D.R., Morphological evolution of thermal barrier coatings induced by cyclic oxidation, Surf.Coat.Tech., 2003, 163-164, 81-86.

[102] Ruud J.A., Bartz A., Borom M.P., Johnson C.A., Strength Degradation and Failure Mechanisms of Electron-Beam Physical-Vapor-Deposited Thermal Barrier Coatings, J. Am. Ceram. Soc., 2001, 84 (7), 1545-52.

[103] Vaßen R., GIESEN S., STOVER D., Lifetime of Plasma-Sprayed Thermal Barrier Coatings: Comparison of Numerical and Experimental Results, Journal of Thermal Spray Technology, 2009, Vol 18(5-6), 835-845. 